\title{
Combined Diagnostic Accuracy of Total Leukocyte Count, Neutrophil Count, and Ultrasonography for the Diagnosis of Acute Appendicitis
}

\author{
Shehzadi Rimsha Fatima ${ }^{1}$, Farhan Zaheer ${ }^{1}$, Foad Ali Moosa ${ }^{1}$, Shehanshah Muhammed Arqam ${ }^{1}$, Raja
} Muhammad Mussab ${ }^{2}$, Muhammad Saad Choudhry ${ }^{1}$

1. General Surgery, Civil Hospital Karachi, Dow University of Health Sciences, Karachi, PAK 2. General Surgery, Jinnah Postgraduate Medical Centre, Karachi, PAK

Corresponding author: Muhammad Saad Choudhry, choudhry.saad@yahoo.com

\begin{abstract}
Acute appendicitis is a common surgical emergency that classically presents with right lower abdominal pain and tenderness on palpation. The diagnosis is often based on clinical examination in order to avoid the complications of surgery delay, yielding a high rate of negative appendectomies. Ultrasonography is a regularly used modality for establishing the diagnosis, whereas abdominal computed tomography (CT) is often used in sonologically equivocal cases. Other parameters include total leukocyte count, granulocytes, C-reactive protein (CRP), leukocyte elastase activity, D-lactate, phospholipase A2, and interleukin-6 (IL-6). We conducted a prospective study to assess the combined accuracy of total leukocyte count, neutrophil count, and ultrasound as an integrated diagnostic tool. The results of these investigations were tabulated and compared to histopathological evidence of acute appendicitis on biopsy (taken as the gold standard) to calculate sensitivity, specificity, positive predictive value, and negative predictive value. Combined sensitivity and specificity were calculated using cross-tabulation, whereas diagnostic accuracy was estimated from the receiver operating curve (ROC) at the optimal cut-off point. The results showed that the absence of inflammatory findings on ultrasound and normal blood parameters (total leukocyte count and neutrophil count) have a high combined diagnostic accuracy and appendicitis may be ruled out.
\end{abstract}

Review began 01/17/2021 Review ended 01/29/2021 Published 02/02/2021

\section{() Copyright 2021}

Fatima et al. This is an open access article distributed under the terms of the Creative Commons Attribution License CC-BY 4.0., which permits unrestricted use, distribution, and reproduction in any medium, provided the original author and source are credited.
Categories: Gastroenterology, General Surgery, Anatomy

Keywords: acute appendicitis, total leukocyte count, neutrophil count, ultrasound, surgical emergency, clinical diagnosis

\section{Introduction}

Acute appendicitis is one of the most common surgical emergencies encountered by surgeons [1]. A typical patient having acute appendicitis presents with initial periumbilical pain that later shifts to the right lower abdomen and exhibits tenderness in the right iliac fossa on palpation. The accuracy of diagnosis based on clinical examination ranges between $76 \%$ and $92 \%$. However, atypical symptoms like colicky abdominal pain, burning micturition, and diarrhea are common and can create difficulty in the establishment of a clinical diagnosis. Early accurate diagnosis in patients who require immediate surgical intervention is very crucial, as a delay can increase the rate of complications [2-3].

General surgeons have had a low threshold for appendectomy based on the clinical diagnosis in order to avoid delay and prevent complications, leading to a higher rate of negative appendectomies. This rate is found to be high (10\%-44\%), even in tertiary care centers with proper diagnostic facilities [4]. Negative appendectomies not only cause physical and emotional stress to patients but also cause a financial burden to the patients and public sector hospitals and increase the physical burden of hospital staff working in hectic emergency situations. This rate can be reduced with the help of tools such as focused abdominal computed tomography scan (FACT) for appendicitis. In a study conducted by Shahani et al., it was observed that FACT has a high sensitivity of $97.61 \%$, specificity of $83.33 \%$, and accuracy of $96.66 \%$ and can prove to be a good alternate for clinically and sonologically equivocal appendicitis [5]. Ali M et al. utilized computed tomography (CT) scans to differentiate perforated from non-perforated appendicitis and to decide on an operative versus non-operative treatment strategy [6]. However, the use of a CT scan as a routine diagnostic tool is not free from pitfalls like radiation hazards, non-availability in all hospitals, the financial cost to patients or hospitals, lack of guidelines, and indications for usage [7].

Ultrasound (U/S) is the most commonly used imaging tool in the emergency department for the diagnosis of acute appendicitis with a sensitivity of $83.7 \%$ and a specificity of $95.9 \%$. It is non-invasive, portable, can be repeated frequently without the fear of radiation exposure, and is less expensive when compared with CT [8]. Researchers have conducted studies on various modalities to find suitable alternatives to CT and U/S. These include total leukocyte count (TLC), granulocytes, C-reactive protein (CRP), leukocyte elastase activity, D-lactate, phospholipase A2, and interleukin-6 (IL-6) [5-7]. Current medical literature displays a wide variation in evidence regarding the use of TLC and differential leukocyte count for the diagnosis of acute appendicitis [9-10]. A prospective study conducted by Ali et al. suggested that if investigations 
like TLC, neutrophil count, CRP, and U/S are not suggestive of acute appendicitis, it can be ruled out [11]. The aim of our study was to find out the combined diagnostic accuracy of TLC, neutrophil count, and U/S for the preoperative diagnosis of acute appendicitis, as it will help reduce the rate of negative appendectomies and improve the overall outcome of the patient.

\section{Materials And Methods}

This prospective study was conducted from November 2019 till May 2020. After receiving approval from the Institutional Review Board, consenting patients meeting inclusion criteria were enrolled in the study at the Department of Surgical Unit 1, Dr. Ruth K.M. Pfau Civil Hospital, Karachi. Patients from both genders were included. A detailed history of the illness and basic demographic information was taken at the time of admission, followed by a clinical examination for features of acute appendicitis. Those with a suspected clinical picture of acute appendicitis, having right lower abdominal pain, rebound tenderness in the right iliac fossa, anorexia, nausea, vomiting, and duration of symptoms within 72 hours were admitted. Exclusion criteria included patients who had an appendicular lump or an appendicular perforation (both assessed by clinical examination), pregnancy with appendicitis (assessed by relevant clinical history), previous history of urolithiasis or pelvic inflammatory disease, previous abdominal surgery or recent abdominal trauma, and failure to get consent.

Blood samples were drawn by the researcher in a disposable syringe under aseptic conditions for complete blood count (which revealed TLC and neutrophil count). TLC count of more than 11,000 cells/ml and neutrophil count of more than $75 \%$ were considered as supportive evidence in favor of acute appendicitis. After lab workup, an ultrasound abdomen was performed for the presence of acute appendicitis. U/S findings were considered positive if they showed a non-compressible, blind-ending, non-peristaltic bowel loop originating from the cecum (appendix), loculated para-cecal collection, and/or the finding of an appendicolith. The surgically excised specimens were sent for histopathology after being fixed in formalin $10 \%$ at the Department of Pathology, Dow Medical College, Civil Hospital, Karachi. A total of 177 samples were collected through the non-probability consecutive sampling technique.

The sample size was calculated by using TLC (sensitivity $76 \%$, specificity $65 \%$ ), the prevalence of acute appendicitis (50\%), the margin of error $(d=10 \%)$, and a confidence interval of $95 \%$ using the Dr. Lin Naing sample size calculator for sensitivity and specificity. The Statistical Package for the Social Sciences (SPSS) version 23.0 (IBM Corp, Armonk, NY) was used for data collection and analysis. The study variables included age, gender, values of TLC and neutrophil count, U/S, and histopathological findings of the appendices. Histopathology reports were taken as the gold standard for diagnosis. Sensitivity, specificity, positive predictive value (PPV), and negative predictive value (NPV) were calculated for each test. Combined sensitivity and specificity were calculated using cross-tabulation. Diagnostic accuracy at the optimal cut-off threshold scores was derived from the receiver operating curve (ROC) for TLC, neutrophil count, and U/S.

\section{Results}

The age range of patients included in our study was 13-60 years and the most prevalent age group in the sample population was found to be 21-30 years (38.8\%). We had 122 (68.8\%) male and 55 (31.2\%) female patients. The histopathology reports of surgically removed appendices showed that $142(80.22 \%)$ cases actually had acute appendicitis (Table 1). 


\section{Cureus}

\begin{tabular}{|c|c|c|c|}
\hline & & Frequency & Percentage (\%) \\
\hline \multirow{5}{*}{ Age } & $13-20$ & 67 & 37.6 \\
\hline & $21-30$ & 69 & 38.8 \\
\hline & $31-40$ & 34 & 19.4 \\
\hline & $41-50$ & 7 & 2.4 \\
\hline & $51-60$ & 5 & 1.8 \\
\hline \multirow{2}{*}{ Gender } & Male & 122 & 68.8 \\
\hline & Female & 55 & 31.2 \\
\hline \multirow{2}{*}{ Histopathology } & Positive & 142 & 80.22 \\
\hline & Negatıve & 35 & 19.18 \\
\hline
\end{tabular}

\section{TABLE 1: Descriptive statistics of age, gender, and histopathology}

The histopathology report showed that 123 out of 128 patients who had TLC $>11,000 / \mathrm{mm}^{3}$ actually had appendicitis (true-positive). While 25 out of 49 patients who had evidence of acute appendicitis on histopathology were false-negative (TLC was $<11,000 / \mathrm{mm}^{3}$ ). The diagnostic accuracy of TLC >

$11,000 / \mathrm{mm}^{3}$ was found to be $82.94 \%$, sensitivity $83.10 \%$, specificity $82.14 \%$, PPV $95.93 \%$, and NPV $48.94 \%$. The area under the curve on ROC was 0.826 (refer to Figure 1 and Table 2).

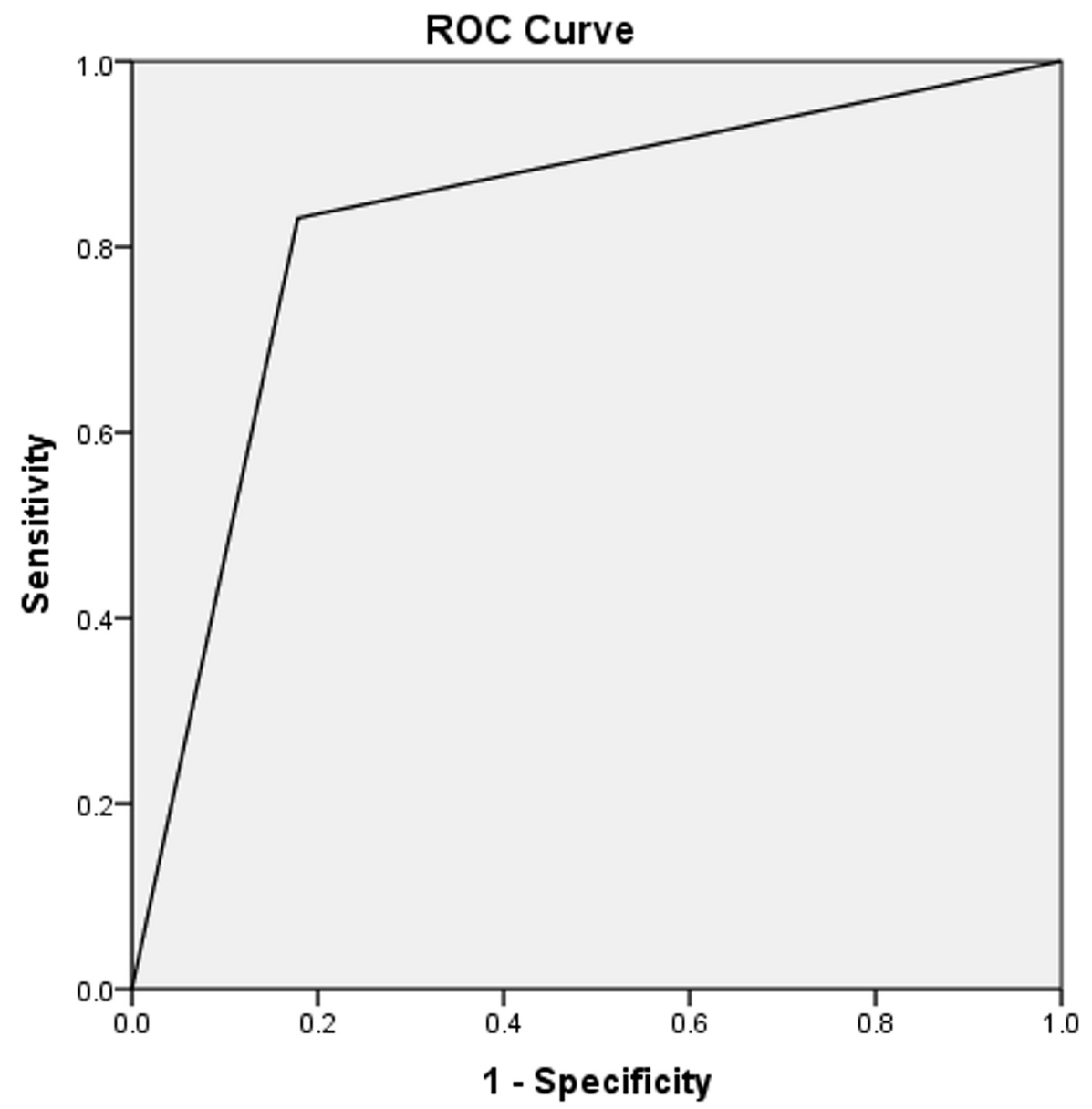

Diagonal segments are produced by ties. 


\section{Cureus}

FIGURE 1: Area under the curve for TLC $>11,000 / \mathrm{mm} 3=0.826$

TLC: total leukocyte count

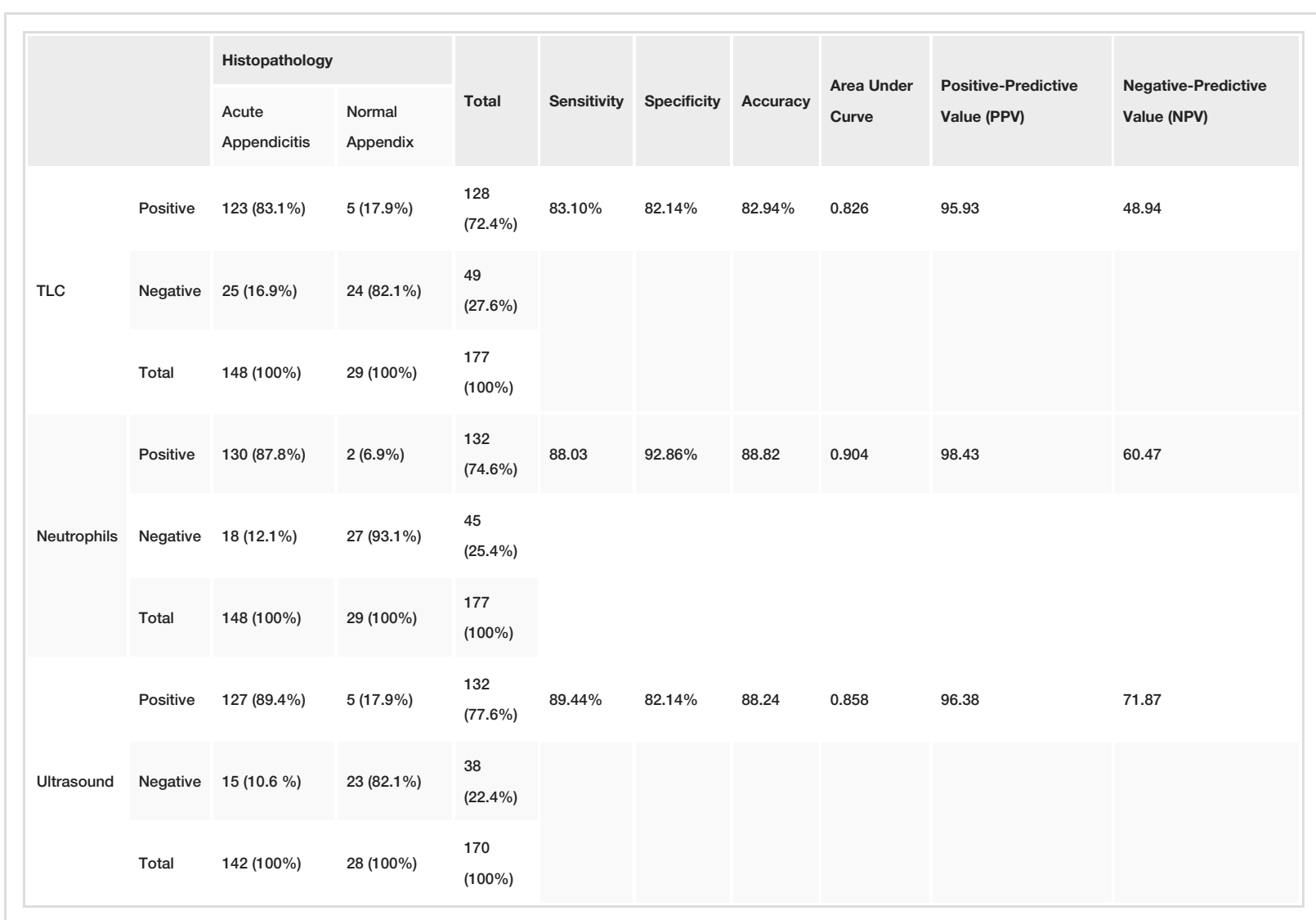

TABLE 2: Describes the comparison of histopathological report findings with TLC, neutrophil count, and ultrasound findings

TLC: total leukocyte count

On the other hand, 130 out of 132 patients who had neutrophil count $>75 \%$ were true-positive on the basis of histopathological findings, whereas 18 out of 45 patients who had evidence of acute appendicitis on histopathology were false-negative (the neutrophil count was $<75 \%$ ). The accuracy of the neutrophil test in this study was calculated to be $88.82 \%$, sensitivity $88.03 \%$, specificity $92.86 \%$, PPV $98.43 \%$, and NPV $60.47 \%$. The area under the curve for the neutrophil count on ROC was 0.904 (refer to Figure 2 and Table 2). 


\section{Cureus}

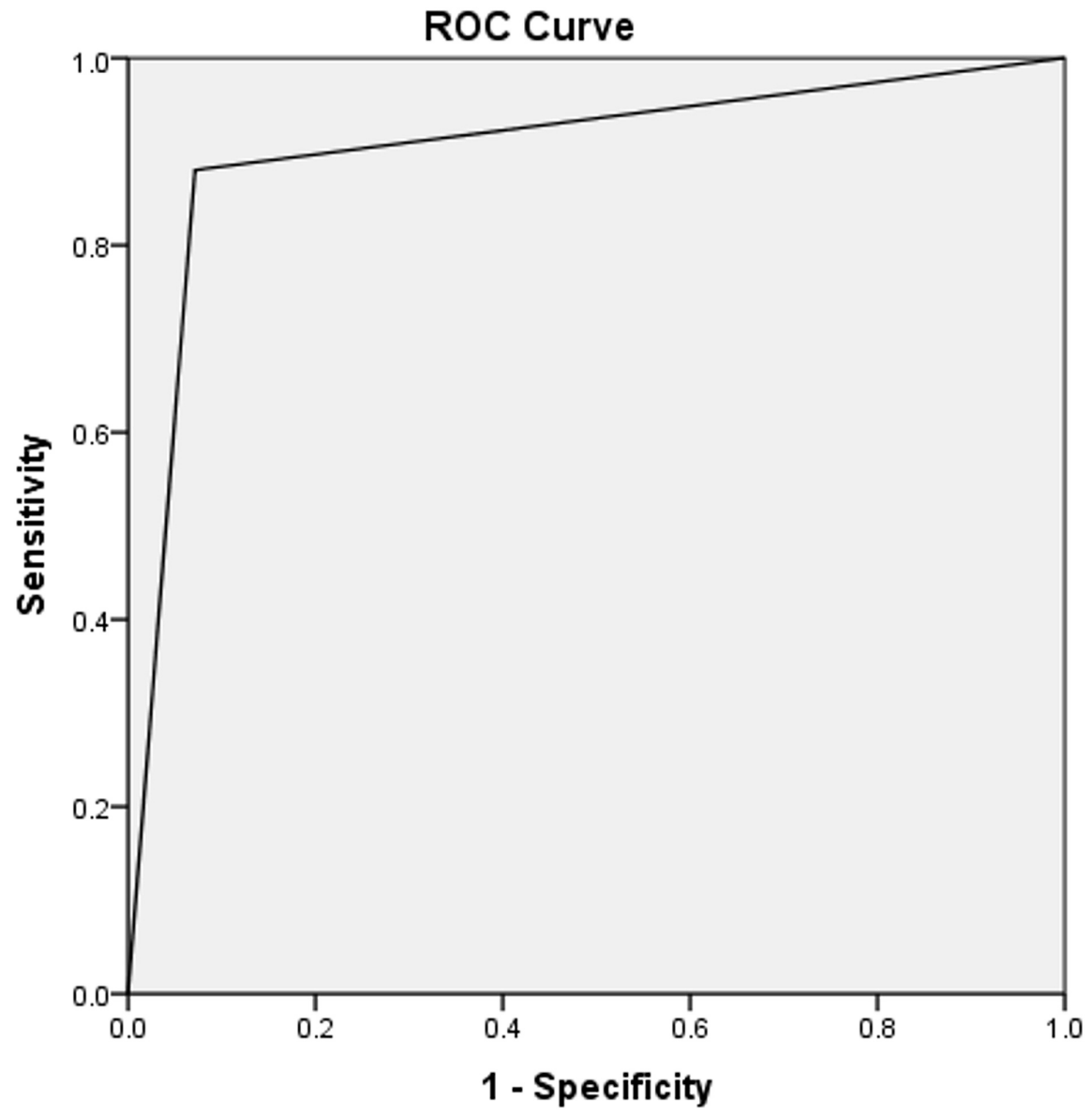

Diagonal segments are produced by ties.

FIGURE 2: Area under the curve for neutrophil count $>75 \%=0.904$

For the U/S scan showing a non-compressible, blind-ending tubular structure and diameter of the appendix $>7 \mathrm{~mm}$. Out of $132 \mathrm{U} / \mathrm{S}$ positive patients, 127 were true-positive based on the histopathological report. In our study, five patients were false-positive, whereas 15 patients were false-negative for acute appendicitis on $\mathrm{U} / \mathrm{S}$ examination. The accuracy of U/S was calculated to be $88.24 \%$, sensitivity $89.44 \%$, specificity $82.14 \%$, PPV 96.38\%, NPV 71.87\%, and area under the curve 0.858 (refer to Figure 3 and Table 2). Possible reasons can be lymphoid hyperplasia, abdominal tuberculosis, salpingitis, or other causes of peritonitis, which may cause inflammatory changes around the appendix similar to acute appendicitis. 


\section{Cureus}

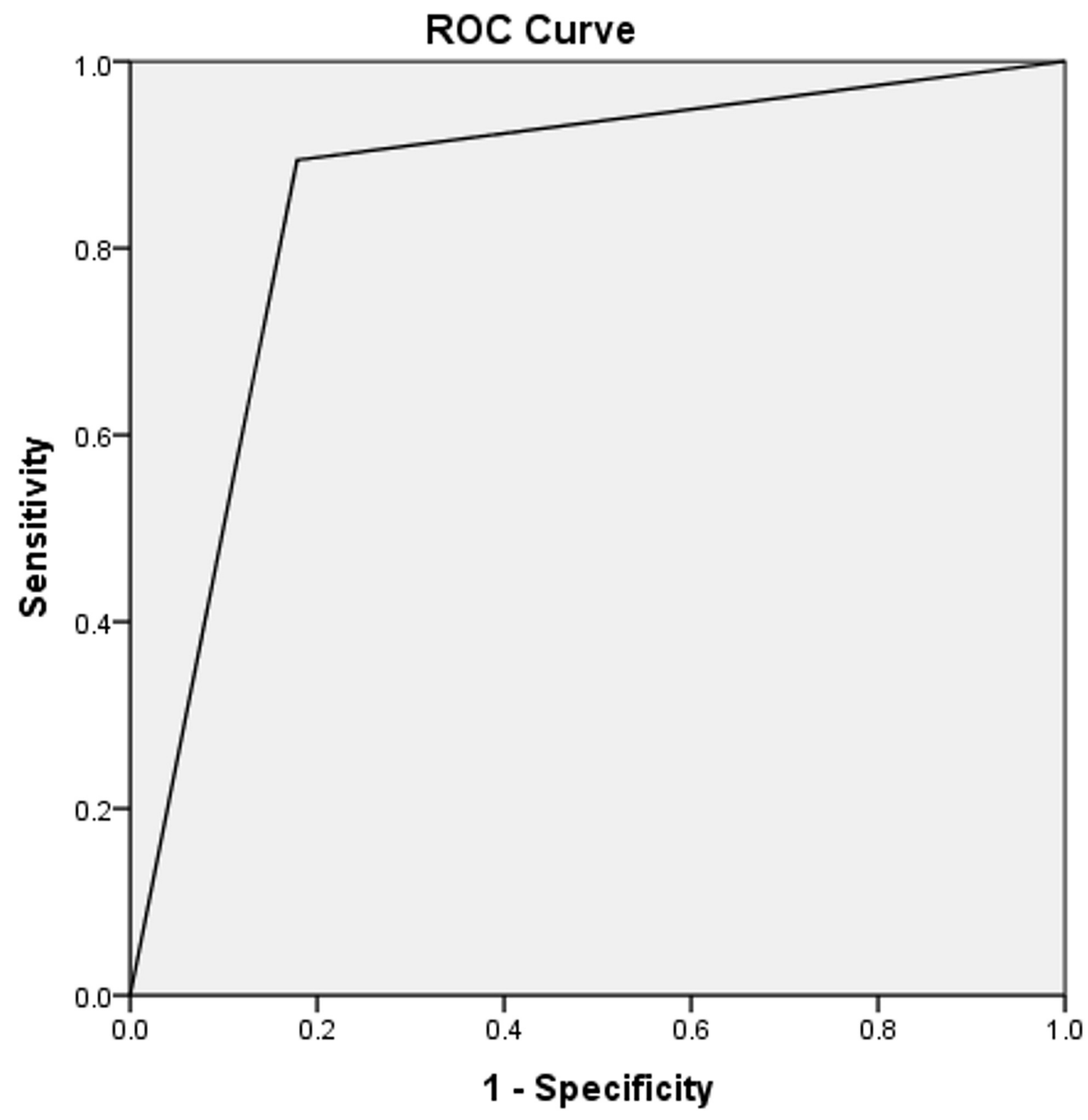

Diagonal segments are produced by ties.

FIGURE 3: Area under the curve for the ultrasound scan $=0.858$

All patients having TLC $>11,000 / \mathrm{mm}^{3}$ along with neutrophil count $>75 \%$ were combined into one group. Ninety-three point seven percent (93.7\%) of these patients were diagnosed with appendicitis on the histopathology report. The accuracy of TLC and neutrophil count combined was found to be $88.24 \%$, sensitivity $89.44 \%$, specificity $82.14 \%$, PPV $96.21 \%$, NPV $60.53 \%$, and area under the curve 0.879 (refer to Table 3 and Figure 4).

\begin{tabular}{|c|c|c|c|c|c|c|c|c|c|}
\hline & & \multicolumn{2}{|c|}{ Histopathology } & \multirow{2}{*}{ Sensitivity } & \multirow{2}{*}{ Specificity } & \multirow{2}{*}{ Accuracy } & \multirow{2}{*}{$\begin{array}{l}\text { Area } \\
\text { Under } \\
\text { Curve }\end{array}$} & \multirow{2}{*}{$\begin{array}{l}\text { Positive-Predictive } \\
\text { Value (PPV) }\end{array}$} & \multirow{2}{*}{$\begin{array}{l}\text { Negative-Predictive } \\
\text { Value (NPV) }\end{array}$} \\
\hline & & $\begin{array}{l}\text { Acute } \\
\text { Appendicitis }\end{array}$ & $\begin{array}{l}\text { Normal } \\
\text { Appendix }\end{array}$ & & & & & & \\
\hline \multirow{2}{*}{ TLC + Neutrophil Count } & Positive & $133(93.7 \%)$ & $5(17.9 \%)$ & $89.44 \%$ & $82.14 \%$ & $88.24 \%$ & 0.879 & $96.21 \%$ & $60.53 \%$ \\
\hline & Negative & $9(6.3 \%)$ & $23(82.1 \%)$ & & & & & & \\
\hline \multirow{2}{*}{$\begin{array}{l}\text { TLC + Neutrophils Count + } \\
\text { Ultrasonography }\end{array}$} & Positive & $138(97.2 \%)$ & $5(17.9 \%)$ & $97.18 \%$ & $82.14 \%$ & $94.71 \%$ & 0.897 & $96.50 \%$ & $85.19 \%$ \\
\hline & Negative & $4(2.8 \%)$ & $23(82.1 \%)$ & & & & & & \\
\hline
\end{tabular}

TABLE 3: Analysis of combined factors (cross-tabulated) 


\section{Cureus}

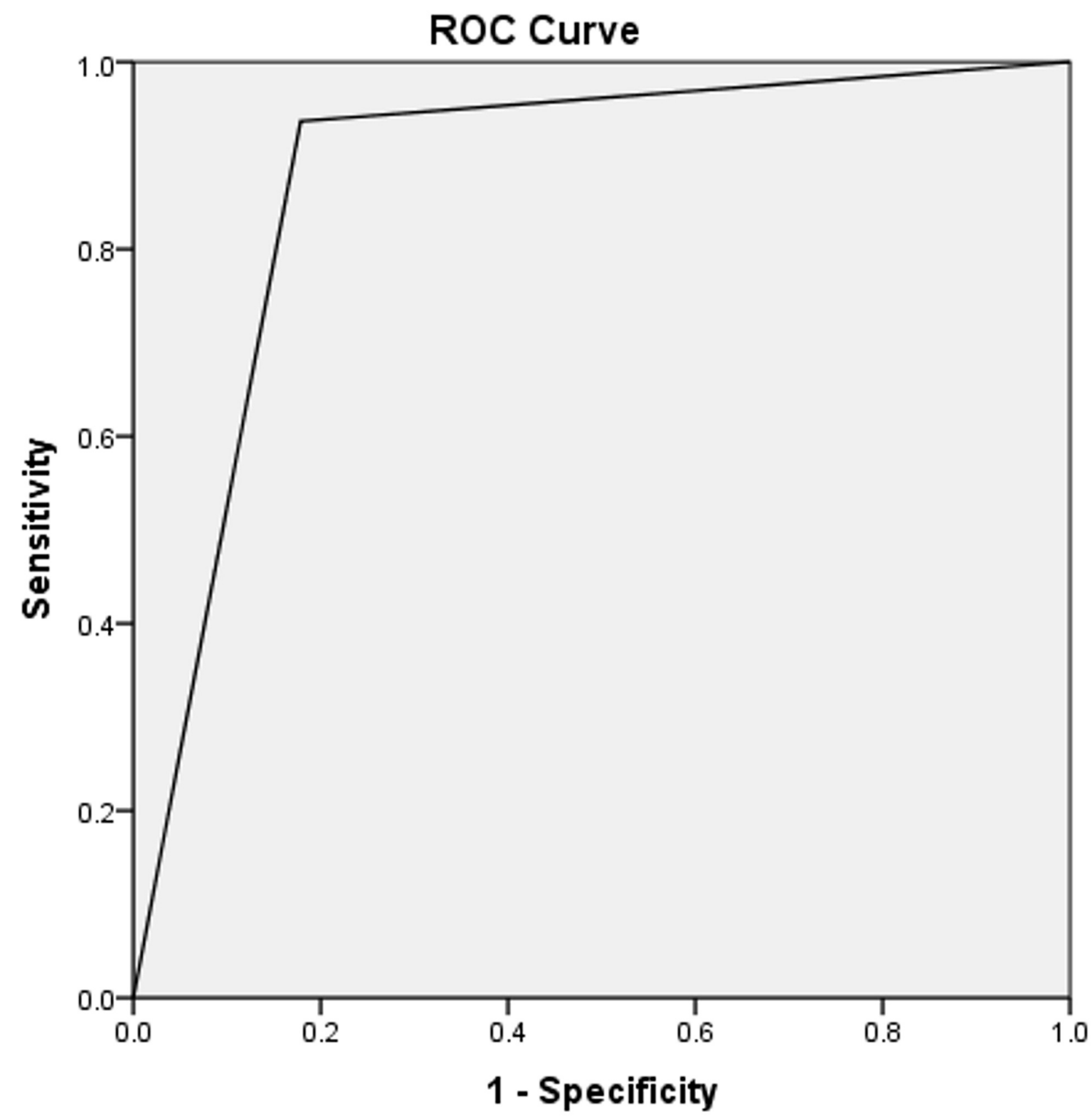

Diagonal segments are produced by ties.

FIGURE 4: Area under the curve for combined TLC and neutrophil count $=0.879$

TLC: total leukocyte count

Likewise, patients having TLC $>11,000 / \mathrm{mm}^{3}$, neutrophil count $>75 \%$, and ultrasonographic features showing non-compressible, blind-ending loop, and diameter of the appendix $>7 \mathrm{~mm}$ were combined into one group. Ninety-seven point two percent (97.2\%) of the patients were diagnosed with appendicitis on histopathology. The combined accuracy, sensitivity, specificity, PPV, and NPV for TLC, neutrophil count, and ultrasonography came out to be $94.71 \%, 97.18 \%, 82.14 \%, 96.50 \%$, and $85.19 \%$, respectively, as shown in Table 3. The combined tests were evaluated by the cross-tabulation method. The area under the curve for combined TLC, neutrophil count, and ultrasound was found to be 0.897 (refer to Table 3 and Figure 5). 


\section{Cureus}

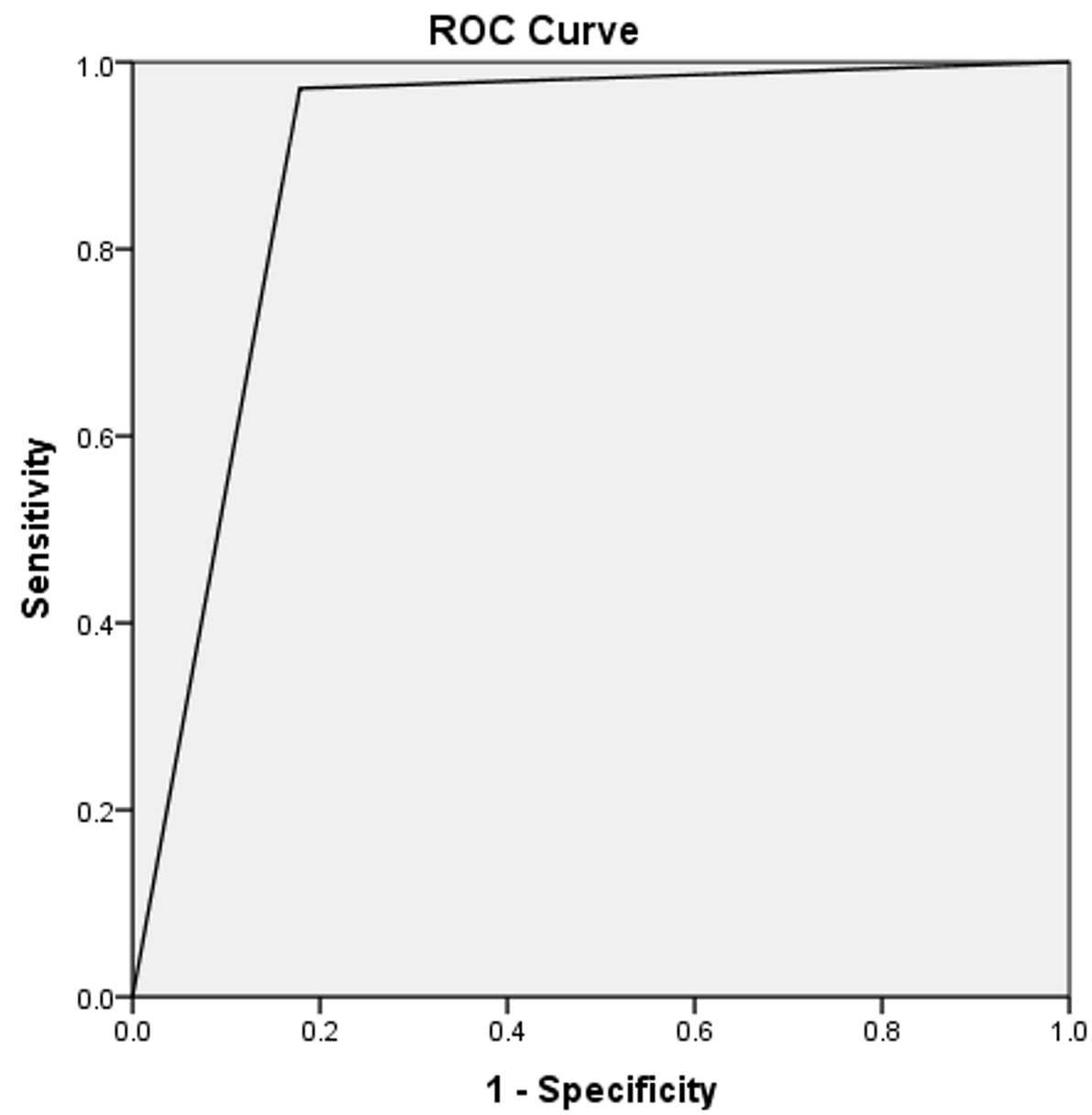

Diagonal segments are produced by ties.

FIGURE 5: Area under the curve for combined TLC, neutrophil count, and $\mathrm{U} / \mathrm{S}=0.897$

TLC: total leukocyte count; U/S: ultrasound

\section{Discussion}

Acute appendicitis is diagnosed clinically in less than $50 \%$ of cases [12]. In many cases, the symptoms are atypical or equivocal and require lab investigations or imaging modalities to support or rule out the diagnosis. Nevertheless, even with the help of these diagnostic tools, the rate of perforation of appendices and the rate of negative laparotomy remains high [13]. Authors in various studies have found that ultrasound and CT have high sensitivity and specificity for atypical and equivocal cases of acute appendicitis. However, these investigations are expensive, have radiation hazards, are operator-dependent, and need a radiologist to interpret findings, especially in equivocal cases. This has created a need to find the right combination of blood markers and radiological investigations; that will help surgeons with limited resources in developing countries to accurately diagnose patients [14].

TLC is a commonly used supportive marker for diagnosis and is reported to be $>11,000 / \mathrm{mm}^{3}$ in $80 \%-90 \%$ of cases of acute appendicitis. In complicated cases, such as gangrene or perforation, it may be raised up to $18,000 / \mathrm{mm}^{3}$ [15]. Similarly, the results of our study showed that TLC was greater than $11,000 / \mathrm{mm}^{3}$ in $83.1 \%$ of patients with histopathological evidence of acute appendicitis. In our study, the accuracy of TLC >

$11,000 / \mathrm{mm}^{3}$ (as a diagnostic tool) was found to be $82.94 \%$, with sensitivity and specificity being $83.10 \%$ and $82.14 \%$, respectively.

Another inflammatory marker, frequently employed for diagnosis, is neutrophil count, which is reported to be greater than $75 \%$ (left shift) in $80 \%-90 \%$ of cases [16]. In our study, $87.8 \%$ of patients having a neutrophil count greater than $75 \%$ were true positive, confirmed on histopathological report findings. The accuracy of the neutrophil percentage was calculated to be $88.82 \%$, sensitivity of $88.03 \%$, and specificity of $92.86 \%$. These recorded results validate the observations made by studies conducted earlier [17-18]. 
Ultrasound is frequently used as the initial imaging modality for the diagnosis of acute appendicitis, especially in pregnant women, children, and the elderly. However, making an accurate diagnosis in obese patients can prove to be difficult [19]. Modern advancements have made it possible to detect the appendix in up to $97 \%$ of cases and the associated inflammatory changes of acute appendicitis, making it a highly sensitive tool. The accuracy of ultrasound in detecting acute appendicitis also depends on the expertise of the radiologist [20]. In our study, 127 out of 132 patients that tested positive on ultrasonography, turned out to be true-positive as confirmed on the histopathological report. The accuracy of U/S was $88.24 \%$, sensitivity was $89.44 \%$, and specificity was $82.14 \%$.

When patients having TLC $>11,000 / \mathrm{mm}^{3}$ and neutrophil count $>75 \%$ were combined into one group, the combined accuracy was found to be $88.24 \%$, sensitivity was $89.44 \%$, and specificity was $82.14 \%$. Lau et al. observed similar results in their study [18]. Similarly, patients having TLC $>11,000 / \mathrm{mm}^{3}$, neutrophil count > $75 \%$, and ultrasound features showing a non-compressible, blind-ending loop and the diameter of the appendix $>7 \mathrm{~mm}$ were combined into one group. The combined results showed a sensitivity of $97.18 \%$, specificity of $82.14 \%$, PPV of $96.50 \%$, and NPV of $85.19 \%$. These results are consistent with studies conducted previously and favor performing routine TLC, neutrophil count, and U/S in patients clinically suspected of having acute appendicitis [21-24]. The NPV for combined TLC and the neutrophil count was $60.53 \%$; however, when U/S was combined with these two investigations, the NPV was $85.19 \%$. Hence, acute appendicitis may be ruled out when these two blood investigations are within the normal range and U/S findings do not show acute inflammatory changes in the appendix and surrounding structures.

The limitations of our study were that it was a single-center study and cannot be termed as truly representative of the entire population so the results cannot be generalized to the whole population. Also, different radiologists performed U/S on patients, depending on availability and working shifts, which could have lead to a wide variation in diagnostic accuracy.

\section{Conclusions}

Patients clinically suspected of having acute appendicitis should be considered for combined TLC, neutrophil count, and U/S for confirmation. Although TLC and neutrophil count individually are not specific for the diagnosis of acute appendicitis and may be raised in other diseases, the combined results of all three investigations yield high accuracy, sensitivity, specificity, PPV, and NPV. A CT scan should be reserved for patients in which acute appendicitis cannot be ruled out with the results of these combined investigations.

\section{Additional Information}

\section{Disclosures}

Human subjects: Consent was obtained or waived by all participants in this study. Animal subjects: All authors have confirmed that this study did not involve animal subjects or tissue. Conflicts of interest: In compliance with the ICMJE uniform disclosure form, all authors declare the following: Payment/services info: All authors have declared that no financial support was received from any organization for the submitted work. Financial relationships: All authors have declared that they have no financial relationships at present or within the previous three years with any organizations that might have an interest in the submitted work. Other relationships: All authors have declared that there are no other relationships or activities that could appear to have influenced the submitted work.

\section{References}

1. Akbar F, Yousuf M, Morgan RJ, Maw A: Changing management of suspected appendicitis in the laparoscopic era. Ann R Coll Surg Engl. 2010, 92:65-68. 10.1308/003588410X12518836439920

2. Subedi N, Dangol U, Adhikary M, Pudasaini S, Baral R: Acute appendicitis: a 2-year review of clinical presentation and histopathology. J Path Nepal. 2011, 1:104-107. 10.3126/jpn.v1i2.5402

3. Khan I, Rehman AU: Application of Alvarado scoring system in diagnosis of acute appendicitis . J Ayub Med Coll Abbottabad. 2005, 17:41-44.

4. Agarwal CS, Adhikari S, Kumar M: Role of serum C-reactive protein and leukocyte count in the diagnosis of acute appendicitis in the Nepalese population. Nepal Med Coll J. 2008, 10:11-15.

5. Shahani BK, Nizamani WM, Vaswani AK, Raza F: Validity of focused abdominal CT scan [FACT] for the diagnosis of acute appendicitis in clinically/sonographically equivocal cases. PJR. 2014, 24:117-122.

6. Ali M, Iqbal J, Sayani R: Accuracy of computed tomography in differentiating perforated from nonperforated appendicitis, taking histopathology as the gold standard. Cureus. 2018, 10:e3735. 10.7759/cureus.3735

7. Debnath J, George RA, Ravikumar R: Imaging in acute appendicitis: what, when, and why? . Med J Armed Forces India. 2017, 73:74-79. 10.1016/j.mjafi.2016.02.005

8. Shogilev DJ, Duus N, Odom SR, Shapiro NI: Diagnosing appendicitis: an evidence-based review of the diagnostic approach in 2014. West J Emerg Med. 2014, 15:859-871. 10.5811/westjem.2014.9.21568

9. Ali N, Rasul SH, Mehmood ZA, Inamullah, Khan A: Value of total leucocyte count and C-reactive proteins in the diagnosis of acute appendicitis. J Surg Pak. 2009, 14:153-156.

10. Al-gaithy ZK: Clinical value of total white blood cells and neutrophil counts in patients with suspected appendicitis: retrospective study. World J Emerg Surg. 2012, 7:32. 10.1186/1749-7922-7-32

11. Ali S, Shah O, Shah M, Ahmed L, Mallik S, Wani N: Role of total leukocyte count, neutrophil percentage, Creactive protein and ultrasonography in the diagnosis of acute appendicitis. Internet J Surg. 2009, 24:1. 
12. Andersson REB: Meta-analysis of the clinical and laboratory diagnosis of appendicitis . Br J Surg. 2004, 91:28-37. 10.1002/bjs.4464

13. Flum DR, Morris A, Koepsell T, Dellinger EP: Has misdiagnosis of appendicitis decreased over time? A population-based analysis. JAMA. 2001, 286:1748-1753. 10.1001/jama.286.14.1748

14. Toorenvliet BR, Wiersma F, Bakker RFR, Merkus JWS, Breslau PJ, Hamming JF: Routine ultrasound and limited computed tomography for the diagnosis of acute appendicitis. World J Surg. 2010, 34:2278-2285. 10.1007/s00268-010-0694-y

15. Ng KC, Lai SW: Clinical analysis of the related factor in acute appendicitis . Yale J Biol Med. 2002, 75:41-45.

16. Hoffmann J, Rasmussen OO: Aids in the diagnosis of acute appendicitis . Br J Surg. 1989, 76:774-779. 10.1002/bjs.1800760803

17. Bower RJ, Bell MJ, Ternberg JL: Diagnostic value of the white blood cell count and neutrophil percentage in the evaluation of abdominal pain in children. Surg Gynecol Obstet. 1981, 152:424-426.

18. Lau WY, HO YC, Chu KW, Yeung C: Leucocyte count and neutrophil percentage in appendicectomy for suspected appendicitis. NZ J Surg. 1989, 59:395-398. 10.1111/j.1445-2197.1989.tb01593.x

19. Mostbeck G, Adam EJ, Nielsen MB, et al.: How to diagnose acute appendicitis: ultrasound first . Insights Imaging. 2016, 7:255-263. 10.1007/s13244-016-0469-6

20. Hernandez JA, Swischuk LE, Angel CA, Chung D, Chandler R, Lee S: Imaging of acute appendicitis: US as the primary imaging modality. Pediatr Radiol. 2005, 35:392-395. 10.1007/s00247-004-1372-8

21. Styrud J, Eriksson S, Segelman J, Granström L: Diagnostic accuracy in 2,351 patients undergoing appendicectomy for suspected acute appendicitis: a retrospective study 1986-1993. Dig Surg. 1999, 16:39-44. 10.1159/000018692

22. Ainippully AM, Kumar SN, Vysakh CN, Arun Preeth V, Somnath P: Role of total leukocyte count in diagnosis of pediatric acute appendicitis: effect of antibiotic administration and duration of onset of symptoms. Int Surg J. 2018, 5:296-299. 10.18203/2349-2902.isj20175914

23. Khan MN, Davie E, Irshad K: The role of white cell count and c-reactive protein in the diagnosis of acute appendicitis. J Ayub Med Coll Abbottabad. 2004, 16:3.

24. West WM, Brady-West DC, McDonald AH, Hanchard B, Fearon-Boothe D: Ultrasound and white blood cell counts in suspected acute appendicitis. West Indian Med J. 2006, 55:100-102. 